\title{
Upland rice breeding in Brazil: a simultaneous genotypic evaluation of stability, adaptability and grain yield
}

\author{
José Manoel Colombari Filho $\cdot$ Marcos Deon Vilela de Resende • \\ Orlando Peixoto de Morais • Adriano Pereira de Castro • \\ Élcio Perpétuo Guimarães · José Almeida Pereira • \\ Marley Marico Utumi • Flávio Breseghello
}

Received: 18 July 2012/Accepted: 4 April 2013/Published online: 23 April 2013

(C) Springer Science+Business Media Dordrecht 2013

\begin{abstract}
The relative performance of one genotype is not identical in different environments due to genotype-environment interaction $(\mathrm{G} \times \mathrm{E})$. Thus, for a breeding program to successfully develop cultivars, it is fundamental that candidate elite-lines are tested in several target environments and that the data are analysed for yield, adaptability and stability. The objective of this work was to study the $\mathrm{G} \times \mathrm{E}$ for upland rice using a mixed model and, using the harmonic mean of relative performance of genotypic values (HMRPGV) method, to analyse cultivars and elite-lines over time to identify those that aggregate high grain yield (GY) with high genotypic adaptability and stability. A large dataset of "value for cultivation and use trials" collected by the Brazilian Agricultural Research Corporation (Embrapa) and collaborators from 1984 to 2010, involving seven states that represent upland rice crops in the
\end{abstract}

J. M. Colombari Filho $(\varangle) \cdot$ O. P. de Morais .

A. P. de Castro · É. P. Guimarães · F. Breseghello

Embrapa Rice and Beans, BP 179, Santo Antônio de

Goiás, GO, Brazil

e-mail: jose.colombari@embrapa.br

M. D. V. de Resende

Embrapa Forests, BP 319, Colombo, PR, Brazil

J. A. Pereira

Embrapa Mid-North, BP 01, Teresina, PI, Brazil

M. M. Utumi

Embrapa Rondonia, BP 405, Vilhena, RO, Brazil
Midwest, North and Northeast regions of Brazil, was used. The effect of location was shown to be more important than the effect of year for promoting crossover interaction. The CNA 8555 had the best GY associated with adaptability and stability, presenting a superiority of $13.28 \%$ above the general mean of all elite-lines. Using already-released cultivars and potential elite-lines, the generalised linear regression analysis revealed significant progress of the stability and adaptability associated with GY over time. The HMRPGV method was shown to be an important tool and allowed identification of three elite-lines in the Embrapa pipeline (AB 062008, AB 062041 and $\mathrm{AB}$ 062037), each with high stability, adaptability and yield potential to be released commercially.

Keywords Oryza sativa $\cdot$ HMRPGV · BLUP . $\mathrm{REML} \cdot \mathrm{G} \times \mathrm{E} \cdot$ Genetic progress
Abbreviations
BLUP Best linear unbiased predictor
REML Restricted maximum likelihood
GY
VCU Value for cultivation and use
$\mathrm{G} \times \mathrm{E} \quad$ Genotype-environment interaction
$\mathrm{G} \times \mathrm{L} \quad$ Genotype-location interaction
$\mathrm{G} \times \mathrm{Y} \quad$ Genotype-year interaction
$\mathrm{G} \times \mathrm{L} \times \mathrm{Y}$ Genotype-location-year interaction
HMRPGV Harmonic mean of relative performance of genotypic values 


\section{Introduction}

In Brazil, upland rice (Oryza sativa L.) was developed as a frontier crop on the savannahs (known as "cerrado" in Portuguese) in the central regions of Brazil and is mainly used to prepare the land for establishment of the next crop. Currently, the upland rice growing areas occur in different locations with diverse climates and varying use of technology (Pinheiro et al. 2006). It is known that the relative performance of one genotype is not identical in different environments due to the occurrence of significant genotype-environment interaction $(\mathrm{G} \times \mathrm{E})$, which particularly affects quantitative traits. Thus, for a breeding program to successfully develop cultivars that are well-adapted to growing regions, it is fundamental that the elite-lines are tested in several target environments and that the data are analysed for yield, adaptability and stability.

The most widely accepted definitions for adaptability and stability are those of Mariotti et al. (1976). Adaptability is the capacity of a genotype to respond favourably to changes in the environment, while stability is the capacity of a genotype to have a highly predictable performance in different environmental conditions. The use of methods that convert measures of adaptability and stability along with yield into a unique value, such as the methods of Annicchiarico (1992) and Lin and Binns (1988), are preferred in practice because they allow a simpler interpretation, especially when there is a need to analyse and interpret an elevated number of genotypes (Cruz et al. 2004). In the context of mixed models, the Harmonic Mean of Relative Performance of Genotypic Values (HMRPGV) method proposed by Resende (2007a) is one of the few methods that uses Restricted Maximum Likelihood (REML) and Best Linear Unbiased Prediction (BLUP) and is similar to the methods of Lin and Binns (1988) and Annicchiarico (1992) but has the advantage of allowing analysis of unbalanced data.

In the HMRPGV method for stability analysis, the genotypes can be simultaneously sorted by genotypic values (yield) and stability using the harmonic means of the BLUP so that the smaller the standard deviation of genotypic performance among the locations, the greater the Harmonic Mean of Genotypic Values $\left(\mathrm{S}_{\mathrm{i}}\right)$. For adaptability analysis, the Relative Performance of Genotypic Values $\left(\mathrm{A}_{\mathrm{i}}\right)$ is measured across environments. In this case, the predicted genotypic values are expressed as a proportion of the general mean for each location, subsequently obtaining the average value of these ratios from all locations. Finally, a simultaneous genotypic analysis of yield, adaptability and stability can be performed using the Harmonic Mean of Relative Performance of Genotypic Values $\left(\mathrm{Z}_{\mathrm{i}}\right)$ (Resende 2007a).

Studies using the HMRPGV method have been conducted with several different species: sugarcane, for total yield (Oliveira et al. 2005) and tonnes of brix per hectare (Bastos et al. 2007; Zeni-Neto et al. 2008); beans, for grain yield (Carbonell et al. 2007); cashews, for productivity (Maia et al. 2009); Hevea brasiliensis, for rubber production (Verardi et al. 2009); and rice, for grain yield in the Minas Gerais state of Brazil (Borges et al. 2010).

Since 1975, the Brazilian Corporation for Agricultural Research (Embrapa) has coordinated an upland rice breeding program in collaboration with other public institutions. The program's efforts have been devoted to improving grain quality and agronomic traits, resistance to biotic stresses, tolerance to abiotic stresses and adaptation to Brazilian growing regions. The large dataset of "value for cultivation and use (VCU) trials" collected during the 27 years of the breeding program and performed in seven of the most important upland rice-growing Brazilian states was used in this work. The objective of this study was to investigate the $\mathrm{GxE}$ and to form a hypothesis of the evolution over time of elite-lines and cultivars based on genotypic evaluation for grain yield, adaptability and stability using the REML/BLUP procedure.

\section{Materials and methods}

Experimental data and details

The experimental data used were taken from VCU trials of upland rice conducted by Embrapa and collaborators during the period between 1984 and 2010. The trait evaluated was grain yield (GY). Each year, trials were composed of nearly 20 genotypes, four of which were check cultivars; the others were elite-lines in the first, second or third year of testing. This dataset was highly unbalanced; i.e., the genotypes that composed the VCU trials varied from year to year 
because of the annual selection of superior elite-lines, the annual discard of those with bad performance, and replacement of old-check cultivars with modern ones. The trials were conducted in a randomised complete block design with four replicates. Plots were composed of four or five rows, which were $5 \mathrm{~m}$ long and had a density of 60 seeds $\mathrm{m}^{-1}$, but for measurement of GY, only the two or three central rows were harvested, discarding $0.5 \mathrm{~m}$ along each border (useful field plot size). The VCU trials were performed similarly to those of commercial production; however, fungal diseases were not chemically controlled to allow selection of elite-lines with genetic resistance.

Only VCU trial entries identified as having appropriate experimental precision for individual analysis for GY were used; i.e., the coefficient of variation was $\leq 25 \%$ and the experimental accuracy was $\geq 0.7$ (Resende and Duarte 2007). Additionally, the elitelines that participated in only one year of the VCU trial were eliminated because of the likely probability that they do not have promising genotypes. Therefore, the dataset was composed of 596 VCU trials involving the seven Brazilian states where most of the upland rice is grown: Goiás, Mato Grosso, Tocantins, Pará, Rondônia, Maranhão and Piauí. The dataset included a total of 264 elite-lines, 81 locations (latitudes from $1^{\circ} 3^{\prime} 57^{\prime \prime}$ to $18^{\circ} 17^{\prime} 37^{\prime \prime} \mathrm{S}$ and longitudes from $42^{\circ} 44^{\prime} 22^{\prime \prime}$ to $63^{\circ} 54^{\prime} 7^{\prime \prime} \mathrm{W}$ ) and 27 years. The average number of genotypes evaluated each year was 31 and varied from 15 (2007) to 61 (1986), and the number of VCU trials per year was, on average, 21, varying from 8 (1990) to 39 (1995). The total number of field plots was 37,925 with an annual average of 1,405 .

Procedures of statistical analysis

Statistical analyses were performed with the software Selegen-REML/BLUP (Resende 2007b) using the following linear mixed model:

$$
\begin{aligned}
\mathrm{y}_{\mathrm{ijkn}}= & \mu+\mathrm{g}_{\mathrm{i}}+\mathrm{b}_{\mathrm{j}(\mathrm{kn})}+\mathrm{l}_{\mathrm{k}}+\mathrm{a}_{\mathrm{n}}+\mathrm{gl}_{\mathrm{ik}}+\mathrm{ga}_{\mathrm{in}}+\mathrm{la}_{\mathrm{kn}} \\
& +\mathrm{gla}_{\mathrm{ikn}}+\varepsilon_{\mathrm{ijkn}},
\end{aligned}
$$

where $y_{i j k n}$ is the observed value of the $i$-th genotype from the $\mathrm{j}$-th replication within the $\mathrm{k}$-th location and $\mathrm{n}$-th year; $\mu$ is general mean; $\mathrm{g}_{\mathrm{i}}$ is the random effect of the $i$-th genotype $(i=1,2, \ldots, I) ; b_{j(k n)}$ is the fixed effect of the $\mathrm{j}$-th replication within the $\mathrm{k}$-th location and $\mathrm{n}$-th year $(j=1,2, \ldots, J) ; l_{k}$ is the random effect of the $k$-th location $(\mathrm{k}=1,2, \ldots, \mathrm{K}) ; \mathrm{a}_{\mathrm{n}}$ is the random effect of the $\mathrm{n}$-th year $(\mathrm{n}=1,2, \ldots, \mathrm{N}) ; \mathrm{gl}_{\mathrm{ik}}$ is the random effect of the genotype-location interaction $(\mathrm{G} \times \mathrm{L})$; $\mathrm{ga}_{\text {in }}$ is the random effect of the genotype-year interaction $(\mathrm{G} \times \mathrm{Y})$; $\mathrm{la}_{\mathrm{kn}}$ is the random effect of the location-year interaction; $\mathrm{gla}_{\mathrm{ikn}}$ is the random effect of the genotype-location-year interaction $(\mathrm{G} \times \mathrm{L} \times \mathrm{Y})$; and $\varepsilon_{\mathrm{ijkn}}$ is experimental error associated with observation (Steel and Torrie 1997).

The matrix form of this model was $\mathrm{y}=\mathrm{Xb}+\mathrm{Zg}+\mathrm{Qa}+\mathrm{Ti}+\mathrm{Wt}+\varepsilon$, in which $\mathrm{y}, \mathrm{b}, \mathrm{g}$, $\mathrm{a}, \mathrm{i}, \mathrm{t}$ and $\varepsilon$ are, respectively, vectors of data, effects of combinations of replication-location-year added to the general mean (fixed), effects of genotype (random), effects of $\mathrm{G} \times \mathrm{Y}$ (random), effects of $\mathrm{G} \times \mathrm{L}$ (random), effects of $\mathrm{G} \times \mathrm{L} \times \mathrm{Y}$ (random), and random errors. $\mathrm{X}, \mathrm{Z}$, $\mathrm{Q}, \mathrm{T}$ and $\mathrm{W}$ are the matrices of incidence of $\mathrm{b}, \mathrm{g}, \mathrm{a}, \mathrm{i}$ and $t$ effects, respectively (Resende 2007b).

The $b$ vector contains the group of the effects of replication within locations and years, locations, years, and location-year interaction (adjusting replication-location-year combinations). The structure of means and variances was given as by Resende (2007a) and, for the adopted model, the equations for the mixed model were as follows:

$$
\left[\begin{array}{ccccc}
X^{\prime} X & X^{\prime} Z & X^{\prime} Q & X^{\prime} T & X^{\prime} W \\
Z^{\prime} X & Z^{\prime} Z+I \lambda_{1} & Z^{\prime} Q & Z^{\prime} T & Z^{\prime} W \\
Q^{\prime} X & Q^{\prime} Z & Q^{\prime} Q+I \lambda_{2} & Q^{\prime} T & Q^{\prime} W \\
T^{\prime} X & T^{\prime} Z & T^{\prime} Q & T^{\prime} T+I \lambda_{3} & T^{\prime} W \\
W^{\prime} X & W^{\prime} Z & W^{\prime} Q & W^{\prime} T & W^{\prime} W+I \lambda_{4}
\end{array}\right]\left[\begin{array}{c}
\hat{b} \\
\tilde{g} \\
\tilde{a} \\
\tilde{i} \\
\tilde{t}
\end{array}\right]=\left[\begin{array}{c}
X^{\prime} y \\
Z^{\prime} y \\
Q^{\prime} y \\
T^{\prime} y \\
W^{\prime} y
\end{array}\right]
$$

Therefore, $\quad \lambda_{1}=\frac{\sigma_{\mathrm{e}}^{2}}{\sigma_{\mathrm{g}}^{2}}=\frac{1-\mathrm{h}^{2}-\mathrm{a}^{2}-\mathrm{i}^{2}-\mathrm{t}^{2}}{\mathrm{~h}^{2}}, \quad \lambda_{2}=\frac{\sigma_{\mathrm{e}}^{2}}{\sigma_{\mathrm{gy}}^{2}}=$ $\frac{1-\mathrm{h}^{2}-\mathrm{a}^{2}-\mathrm{i}^{2}-\mathrm{t}^{2}}{\mathrm{a}^{2}}, \lambda_{3}=\frac{\sigma_{\mathrm{e}}^{2}}{\sigma_{\mathrm{gl}}^{2}}=\frac{1-\mathrm{h}^{2}-\mathrm{a}^{2}-\mathrm{i}^{2}-\mathrm{t}^{2}}{\mathrm{i}^{2}}$ and $\lambda_{4}=\frac{\sigma_{\mathrm{e}}^{2}}{\sigma_{\mathrm{gly}}^{2}}=$ $\frac{1-\mathrm{h}^{2}-\mathrm{a}^{2}-\mathrm{i}^{2}-\mathrm{t}^{2}}{\mathrm{t}^{2}}$, where, $\sigma_{\mathrm{e}}^{2}$ is the residual variance; $\sigma_{\mathrm{g}}^{2}$ is the genotypic variance between elite-lines; $\sigma_{\mathrm{gy}}^{2}$ is the variance of $\mathrm{G} \times \mathrm{Y}$; $\sigma_{\mathrm{gl}}^{2}$ is the variance of $\mathrm{G} \times \mathrm{L}$; $\sigma_{\mathrm{gly}}^{2}$ is the variance of $\mathrm{G} \times \mathrm{L} \times \mathrm{Y} ; \mathrm{h}^{2}$ is the broad-sense heritability at the individual plot level equal to $\frac{\sigma_{\mathrm{g}}^{2}}{\sigma_{\mathrm{g}}^{2}+\sigma_{\mathrm{gl}}^{2}+\sigma_{\mathrm{ga}}^{2}+\sigma_{\mathrm{gla}}^{2}+\sigma_{\mathrm{e}}^{2}}$; and $\mathrm{a}^{2}, \mathrm{i}^{2}$ and $\mathrm{t}^{2}$ are the determination coefficients of those effects, respectively $c_{\mathrm{gy}}^{2}, c_{\mathrm{gl}}^{2}$ and $c_{\text {gly }}^{2}$ (Resende 2007a).

The genotypic correlations of genetic material across locations and/or years, were obtained using the following equations: $r_{\mathrm{gl}}=\frac{\sigma_{\mathrm{g}}^{2}}{\sigma_{\mathrm{g}}^{2}+\sigma_{\mathrm{gl}}^{2}}$ is the genotypic correlation of genetic material across locations for any year and $r_{\mathrm{gl}} \mathrm{y}=\frac{\left(\sigma_{\mathrm{g}}^{2}+\sigma_{\mathrm{gg}}^{2}\right)}{\left(\sigma_{\mathrm{g}}^{2}+\sigma_{\mathrm{gy}}^{2}\right)+\sigma_{\mathrm{gl}}^{2}}$ for a given year; $\mathrm{r}_{\mathrm{gy}}=$ 
$\frac{\sigma_{\mathrm{g}}^{2}}{\sigma_{\mathrm{g}}^{2}+\sigma_{\mathrm{gy}}^{2}}$ is the genotypic correlation of genetic material across years for any location and $r_{g_{-} 1}=\frac{\left(\sigma_{\mathrm{g}}^{2}+\sigma_{\mathrm{gl}}^{2}\right)}{\left(\sigma_{\mathrm{g}}^{2}+\sigma_{\mathrm{gl}}^{2}\right)+\sigma_{\mathrm{gy}}^{2}}$ for a given location; and $r_{\mathrm{gly}}=\frac{\sigma_{\mathrm{g}}^{2}}{\sigma_{\mathrm{g}}^{2}+\sigma_{\mathrm{gy}}^{2}+\sigma_{\mathrm{gl}}^{2}+\sigma_{\mathrm{gly}}^{2}}$ is the genotypic correlation of genetic material across locations and years.

In the genotypic evaluation, the proximity between predicted genotypic values (BLUP) and true values was evaluated by the estimation of individual accuracy $\left(\hat{\mathrm{r}}_{\hat{\mathrm{g} g}}\right)$ using the equation $\left[1-\left(\mathrm{V} / \hat{\sigma}_{\mathrm{g}}^{2}\right)\right]^{0.5}$, where $\mathrm{V}$ is the prediction error variance, or the variance of genetic values around the estimated value, obtained by inverting the coefficient matrix of the mixed model equations and taking its respective diagonal elements (Henderson 1984). The $\hat{r}_{\hat{g} g}$ value varies from 0 to 1 and can be classified as very high $\left(\hat{\mathrm{r}}_{\hat{\mathrm{g} g}} \geq 0.90\right)$, high $\left(0.70 \leq \hat{\mathrm{r}}_{\hat{\mathrm{gg}}}<0.90\right)$, moderate $\left(0.50 \leq \hat{\mathrm{r}}_{\hat{\mathrm{gg}}}<0.70\right)$ and low $\left(\hat{\mathrm{r}}_{\hat{g} \mathrm{~g}}<0.50\right)$ (Resende and Duarte 2007).

The Harmonic Mean of Genotypic Values $\left(\mathrm{S}_{\mathrm{i}}\right)$ were calculated using the equation $S_{i}=\frac{\ell}{\sum_{j=1}^{\ell} \frac{1}{G_{i j}}}$; the Relative Performance of Genotypic Values $\left(\mathrm{A}_{\mathrm{i}}\right)$ was calculated with $A_{i}=\frac{1}{\ell}\left(\frac{\sum_{j=1}^{\ell} G_{i j}}{M_{j}}\right)$; and the Harmonic Mean of Relative Performance of Genotypic Values $\left(\mathrm{Z}_{\mathrm{i}}\right)$ was calculated with $\mathrm{Z}_{\mathrm{i}}=\frac{\ell}{\sum_{\mathrm{j}=1}^{\ell} \frac{1}{\mathrm{~A}_{\mathrm{i}}}}$, where $\ell$ is the number of test locations of the $i$-th genotype; $G_{i j}$ is the genotypic value of the $\mathrm{i}$-th genotype in the $\mathrm{j}$-th location; and $\mathrm{M}_{\mathrm{j}}$ is the general mean for each location j.

\section{Results and discussion}

This study revealed results of a large dataset involving a wide range of locations, years, input levels and genotypes. Initially, estimates of variance components were obtained, which allowed analysis of the genetic structure of the elite-lines set and their interactions with environments to generate important information to direct the selection process of upland rice breeding programs in Brazil (Table 1). For this, the elite-lines set was considered a "population" resulting from a random sampling of the germplasm present in the upland rice breeding program during this period. The results of the joint analysis (Brazil) revealed a low estimate of broad-sense individual heritability $\left(\mathrm{h}^{2}\right)$ and low deviations equal to $0.0583 \pm 0.0036$ (Table 1 ), which were expected because $h^{2}$ was calculated on an individual plot level and not on a mean plot level. Additionally, this value of $h^{2}$ was consistent with the quantitative nature of GY and was free of all effects of interactions between genotypes, locations and years. Tocantins was the state that presented the lowest value of $\mathrm{h}^{2}$, and Goiás presented the highest value, although it was still considered low (Table 1).

For Brazil, the determination coefficients of interactions between effects of genotype-year $\left(c_{\mathrm{gy}}^{2}\right)$, genotype-location $\left(\mathrm{c}_{\mathrm{gl}}^{2}\right)$ and genotype-location-year $\left(\mathrm{c}_{\mathrm{gly}}^{2}\right)$ were $2.27,6.65$ and $26.37 \%$, respectively (Table 1 ). These values refer to the proportion of phenotypic variance explained by these interactions. Therefore, the $\mathrm{G} \times \mathrm{Y}$ followed by $\mathrm{G} \times \mathrm{L}$ had the lowest proportion; however, the triple interaction had the highest proportion, with a magnitude of approximately $\frac{1}{4}$ of the total phenotypic variance, mostly likely due to the high input of locations and years in the joint analysis.

Observing the variance components of the joint analysis (Table 1), it can be verified that the estimate of genotypic variance $\left(\hat{\sigma}_{\mathrm{g}}^{2}=32,484\right)$ had a similar proportion to the estimate of $\mathrm{G} \times \mathrm{L}$ variance $\left(\hat{\sigma}_{\mathrm{gl}}^{2}=37,011\right)$. The high $\hat{\sigma}_{\mathrm{g}}^{2}$ value resulted from the wide genetic variability present in this set of 264 elitelines tested, and the $\hat{\sigma}_{\mathrm{gl}}^{2}$ value is explained by the geographical vastness of the locations, with a wide diversity of soil and climate conditions. However, the estimate of $\mathrm{G} \times \mathrm{Y}$ variance had a much lower magnitude $\left(\hat{\sigma}_{\text {gy }}^{2}=12,634\right)$, while the triple interaction $\left(\hat{\sigma}_{\text {gly }}^{2}\right)$ was distinguished by a high magnitude $\sim 4.5$ times larger than that of $\hat{\sigma}_{\mathrm{g}}^{2}$. Goiás state had the largest number of elite-lines tested, which is likely what caused it to have the highest value of $\hat{\sigma}_{\mathrm{g}}^{2}$ among all Brazilian states.

The $\mathrm{G} \times \mathrm{E}$ can be divided into two broad types: crossover interaction and non-crossover interaction (Vencovsky and Barriga 1992; Singh and Payasi 1999). The $\mathrm{G} \times \mathrm{E}$ is considered as crossover interaction when genotype ranks change from one environment to another. The non-crossover interaction, on the other hand, results in differential change of mean, but not of ranking of different genotypes (Kang 1998). In plant breeding, the crossover interaction is more important then non-crossover interaction 
Table 1 Estimates of variance components and genetic parameters for grain yield $\left(\mathrm{kg} \mathrm{ha}^{-1}\right)$ obtained by joint analysis of a dataset from Brazil and from each Brazilian state in the period from 1984 to 2010

\begin{tabular}{lllllllll}
\hline Estimate $^{\mathrm{a}}$ & Brazil $^{\mathrm{b}}$ & Goiás & Mato Grosso & Pará & Tocantins & Rondônia & Maranhão & Piauí \\
\hline$\hat{\sigma}_{\mathrm{g}}^{2}$ & 32,484 & 62,959 & 32,381 & 36,646 & 3,488 & 23,436 & 25,978 & 25,460 \\
$\hat{\sigma}_{\text {gy }}^{2}$ & 12,634 & 19,434 & 10,611 & 34,171 & 45,302 & 49,618 & 18,052 & 5,856 \\
$\hat{\sigma}_{\text {gl }}^{2}$ & 37,011 & 57,600 & 34,230 & 18,766 & 34,808 & 10,159 & 18,775 & 4,756 \\
$\hat{\sigma}_{\text {gly }}^{2}$ & 146,806 & 155,421 & 103,586 & 152,652 & 164,895 & 117,641 & 154,682 & 161,489 \\
$\hat{\sigma}_{\mathrm{e}}^{2}$ & 327,801 & 357,792 & 330,267 & 226,257 & 396,304 & 352,390 & 309,698 & 275,879 \\
$\hat{\mathrm{h}}^{2}$ & 0.0583 & 0.0964 & 0.0634 & 0.0782 & 0.0054 & 0.0424 & 0.0493 & 0.0538 \\
& \pm 0.0036 & \pm 0.0080 & \pm 0.0075 & \pm 0.0117 & \pm 0.0046 & \pm 0.0100 & \pm 0.0124 & \pm 0.0127 \\
$\mathrm{c}_{\text {gy }}^{2}$ & 0.0227 & 0.0298 & 0.0208 & 0.0729 & 0.0703 & 0.0897 & 0.0342 & 0.0124 \\
$\mathrm{c}_{\text {gl }}^{2}$ & 0.0665 & 0.0882 & 0.0670 & 0.0401 & 0.0540 & 0.0184 & 0.0356 & 0.0101 \\
$\mathrm{c}_{\text {gly }}^{2}$ & 0.2637 & 0.2379 & 0.2027 & 0.3258 & 0.2557 & 0.2126 & 0.2934 & 0.3411 \\
$\mathrm{r}_{\mathrm{gl}}$ & 0.4674 & 0.5222 & 0.4861 & 0.6613 & 0.0911 & 0.6976 & 0.5805 & 0.8426 \\
$\mathrm{r}_{\mathrm{gy}}$ & 0.7200 & 0.7641 & 0.7532 & 0.5175 & 0.0715 & 0.3208 & 0.5900 & 0.8130 \\
$\mathrm{r}_{\mathrm{gl}-\mathrm{y}}$ & 0.5494 & 0.5886 & 0.5567 & 0.7905 & 0.5836 & 0.8779 & 0.7011 & 0.8681 \\
$\mathrm{r}_{\mathrm{gy}} 1$ & 0.8462 & 0.8612 & 0.8626 & 0.6186 & 0.4581 & 0.4037 & 0.7126 & 0.8377 \\
$\mathrm{r}_{\text {gly }}$ & 0.1419 & 0.2131 & 0.1791 & 0.1513 & 0.0140 & 0.1167 & 0.1195 & 0.1289 \\
$\bar{M}$ & 3,200 & 3,183 & 3,045 & 3,415 & 3,330 & 3,186 & 3,410 & 3,355 \\
\hline
\end{tabular}

${ }^{\mathrm{a}} \hat{\mathrm{h}}^{2}$, broad-sense heritability at the individual plot level; $\mathrm{c}_{\mathrm{gy}}^{2}$, determination coefficient of the effects of genotype-year interaction; $\mathrm{c}_{\mathrm{gl}}^{2}$, determination coefficient of the effects of genotype-location interaction; $c_{\text {gly }}^{2}$, determination coefficient of the effects of genotypelocation-year interaction; $r_{\mathrm{gl}}$, genotypic correlation of genetic material across locations, valid for any year; $r_{\mathrm{gy}}$, genotypic correlation of genetic material across years, valid for any location; $r_{\mathrm{gl} \_\mathrm{y}}$, genotypic correlation of genetic material across locations, in a given year; $r_{\text {gy_l }}$, genotypic correlation of genetic material across years, in a given location; $r_{\text {gly }}$, genotypic correlation of genetic material across locations and years; $\hat{\sigma}_{\mathrm{e}}^{2}$, estimate of residual variance; $\hat{\sigma}_{\mathrm{g}}^{2}$, estimate of genotypic variance between elite-lines; $\hat{\sigma}_{\mathrm{gy}}^{2}$, estimate of variance of genotype-year interaction; $\hat{\sigma}_{\text {gl }}^{2}$, estimate of variance of genotype-location interaction; $\hat{\sigma}_{\text {gly }}^{2}$, estimate of variance of genotype-location-year interaction; and $\overline{\mathrm{M}}$, general mean

b Joint analysis considering the seven Brazilian states

(Baker 1990), because these affect the genotypes to be selected in a given environment. Such interactions also suggest that genotypes are specifically adapted to environments (Singh et al. 1999). However, the non-crossover interaction influences the nature and magnitude of components of genetic variances and other related parameters like heritability and genetic advance. Thus, the non-crossover interaction is represented by $\left[\frac{1}{2}\left(\sigma_{\mathrm{g}_{\mathrm{i}}}-\sigma_{\mathrm{g}_{\mathrm{j}}}\right)^{2}\right]$, where $\sigma_{\mathrm{gi}}$ and $\sigma_{\mathrm{gj}}$ are the genetic standard deviations in environments $i$ and $\mathrm{j}$, respectively (Cockerham 1963). The crossover interaction is represented by $\left[\left(1-\mathrm{r}_{\mathrm{g}_{\mathrm{i}} \mathrm{g}_{\mathrm{j}}}\right) \sigma_{\mathrm{g}_{\mathrm{i}}} \sigma_{\mathrm{g}_{\mathrm{j}}}\right]$, where $r_{\text {gigj }}$ is the genetic correlation of genotype performance between environments $\mathrm{i}$ and $\mathrm{j}$ (Cockerham 1963). From simulation studies, it was suggested that $\mathrm{G} \times \mathrm{E}$ will be predominantly non-crossover when $r_{\text {gigj }} \geq 0.80$ and crossover when $r_{\text {gigj }} \leq 0.20$ (Cruz and Castoldi 1991).
For Brazil, the genotypic correlations across locations and/or years, designated as $\mathrm{r}_{\mathrm{gl}}, \mathrm{r}_{\mathrm{gy}}, \mathrm{r}_{\mathrm{gl}{ }_{-} \mathrm{y}}, \mathrm{r}_{\mathrm{gy} \_}$and $\mathrm{r}_{\text {gly }}$, were $0.4674,0.7200,0.5494,0.8462$ and 0.1419 , respectively (Table 1 ). The $r_{g 1}$ and $r_{g 1 \_y}$ values had median magnitudes, indicating a high level of $\mathrm{G} \times \mathrm{L}$ with a considerable occurrence of crossover interaction. Therefore, genotype rankings based on GY were not identical across locations, which makes the selection of cultivars with wide adaptation difficult; i.e., the recommendation for cultivars should be made for each location or for one set of locations (regions) with high $r_{g 1}$. However, the magnitudes of $r_{g y}$ and $r_{g y \_} 1$ were high, indicating that the genotype rankings have tended to remain constant across years (non-crossover interaction) for any location $\left(\mathrm{r}_{\mathrm{gy}}\right)$ and for a given location $\left(\mathrm{r}_{\mathrm{gy} \_}\right)$. Atroch et al. (2000) and Borges et al. (2010) obtained results that corroborated this study, identifying $\mathrm{G} \times \mathrm{L}$ as more expressive than the $\mathrm{G} \times \mathrm{Y}$ for 
upland rice in Minas Gerais state. Throughout the 27 years of upland rice VCU trials, the effect of location was much more important than the effect of year (climate variations) for promoting crossover interaction, suggesting that for greater effectiveness of selection, the elite-lines should be tested with a wider number of locations than years, as GY was more inconsistent across locations (Vencovsky and Barriga 1992).

Tocantins state showed the highest incidence of crossover interaction, while Piauí state presented noncrossover interaction by location $\left(\mathrm{r}_{\mathrm{gl}}\right)$ and year $\left(\mathrm{r}_{\mathrm{gy}}\right)$. Therefore, a completely different strategy for cultivar selection in each of these two states should be suggested, as discussed above (Table 1). In other species, Bastos et al. (2007) considered an $r_{\mathrm{gl}}$ value of 0.49 as median magnitude, studying tonnes of brix per hectare $\left(\mathrm{t} \mathrm{ha}^{-1}\right)$ in sugarcane; Oliveira et al. (2005) also obtained an $r_{\mathrm{gl}}$ value with median magnitude (0.62) through evaluation of sugarcane yield. However, in beans, Carbonell et al. (2007) obtained an $r_{\mathrm{gl}}$ value of 0.085 for GY, revealing a strong crossover $\mathrm{G} \times \mathrm{L}$.

The ranking by predicted genotypic values $\left(\mathrm{G}_{\mathrm{i}}\right)$ of the 264 elite-lines presented a wide variability for GY, with an amplitude of $800 \mathrm{~kg} \mathrm{ha}^{-1}$ (Table 2). The estimates of individual accuracy ( $\hat{\mathrm{r}}_{\hat{\mathrm{gg}}}$ ) for each eliteline, which depend mainly on the number of environments (locations and years) in which each elite-line was tested, had an average value of 0.7061 (considered high). The $\hat{r}_{\mathrm{g} g}$ values varied from 0.3948 (from CNA 6226, considered low) to 0.9625 (from BRS Primavera, considered very high), and about $\frac{2}{3}$ of the elitelines presented $\hat{\mathrm{r}}_{\hat{\mathrm{gg}} \mathrm{g}}$ values above that recommended by Resende and Duarte (2007), i.e., $\hat{\mathrm{r}}_{\hat{g} g} \geq 0.70$, guaranteeing the quality of the predicted genotypic values for $\mathrm{GY}\left(\mathrm{G}_{\mathrm{i}}\right)$.

In Table $2, S_{i}$ refers to the predicted genotypic value for $\mathrm{GY}\left(\mathrm{kg} \mathrm{ha}^{-1}\right)$ penalised by instability, allowing detection of both stable and high-yielding genotypes. Therefore, the best elite-lines for $S_{i}$ must present consistency in performance year after year, due to the low temporal variability, and location by location, due to the low spatial variability; i.e., the best elite-lines are those with highly predictable performance given variations in environmental conditions. The $A_{i}$ results from the capacity of genotypes to respond favourably to environmental changes
(Table 2) and can be measured on the same scale as GY $\left(\mathrm{kg} \mathrm{ha}^{-1}\right)$ when the $A_{i}$ value is multiplied by the general mean $(\overline{\mathrm{M}})$ of all locations and years $\left(3,200 \mathrm{~kg} \mathrm{ha}^{-1}\right.$, Table 1$)$, obtaining the mean genotypic value $\left(A_{i} \bar{M}\right)$ capitalised by the interaction. Finally, $Z_{i}$ allows for simultaneous evaluation of yield, adaptability and stability through a unique value (Table 2), which can be multiplied by $\bar{M}$, resulting in genotypic values of each elite-line $\left(Z_{i} \bar{M}\right)$ penalised by instability and capitalised by $\mathrm{G} \times \mathrm{E}$.

The top 25 elite-lines ranked by genotypic mean GY $\left(\mathrm{G}_{\mathrm{i}}\right)$ did not coincide with the top 25 elite-lines ranked by $Z_{i}$ (Table 2), with a percentage of coincidence of $84 \%$ and a Spearman correlation of 0.51 (Steel and Torrie 1997). In addition to the occurrence of changes in the ranking positions of the coincident elite-lines, other attributes, such as adaptability and stability of the genotypic values, needed to be taken into account. These results reinforce the need to use, whenever possible, different criteria together with mean GY, as it would provide a better basis for the selection of superior genotypes.

The CNA 8555 had the best $\mathrm{GY}\left(\mathrm{G}_{\mathrm{i}}\right)$ associated with adaptability and stability (Table 2 ), occupying the 1 st position for all parameters $\left(\mathrm{S}_{\mathrm{i}}, \mathrm{A}_{\mathrm{i}}\right.$ and $\left.\mathrm{Z}_{\mathrm{i}}\right)$. This elite-line participated in two years of VCU trials (1998 and 1999), but it was not released as a new cultivar due to low grain quality. The superiority of this elite-line was $13.28 \%\left(\mathrm{Z}_{\mathrm{i}}\right)$ above the general mean of all elitelines tested, which corresponded to a $\mathrm{Z}_{\mathrm{i}} \overline{\mathrm{M}}$ value of $3,625 \mathrm{~kg} \mathrm{ha}^{-1}$.

Among the 25 best elite-lines according to rankings for $G Y\left(G_{i}\right)$, eight elite-lines debuted in the last six years of the VCU trials (2005-2010), illustrating the current success that is being experienced by the upland rice breeding program (Table 2). Additionally, among these, there are five commercial cultivars: Uruçuí, BRS Esmeralda, BRS Colosso, BRS Liderança and BRS Pepita. Uruçuí was released in 1993 and, despite having a high yield $\left(\mathrm{G}_{\mathrm{i}}\right)$, it has not been evaluated in three states (Pará, Rondônia and Maranhão). Thus, its high adaptability $\left(\mathrm{A}_{\mathrm{i}}\right)$ and good stability $\left(\mathrm{S}_{\mathrm{i}}\right)$ could be over-estimated. BRS Colosso and BRS Liderança were released by Embrapa in 2003 and 2004, respectively. They were characterised by high $G Y\left(G_{i}\right)$ and great adaptability and/or stability $\left(\mathrm{A}_{\mathrm{i}}, \mathrm{S}_{\mathrm{i}}\right.$ and $\mathrm{Z}_{\mathrm{i}}$, Table 2). The performances of these cultivars were very similar, likely because they have a full-sib 
Table 2 The twenty-five best genotypes, the lowest genotype, and other upland rice cultivars considering the predicted genotypic value $\left(\mathrm{G}_{\mathrm{i}}\right)$ for grain yield $\left(\mathrm{kg} \mathrm{ha}^{-1}\right)$. In the first year of VCU trials, estimates of the accuracy $\left(\hat{\mathrm{r}}_{\mathrm{gg}}\right)$, stability of genotypic value $\left(\mathrm{S}_{\mathrm{i}}\right)$, adaptability of genotypic value $\left(\mathrm{A}_{\mathrm{i}}\right)$, and stability and adaptability of genotypic value $\left(Z_{i}\right)$, based on the joint analysis of a dataset from seven Brazilian states in the period from 1984 to 2010

\begin{tabular}{|c|c|c|c|c|c|c|c|c|c|c|}
\hline Elite-line & VCU & $\hat{\mathrm{r}}_{\hat{\mathrm{g} g}}$ & Ranking & $\mathrm{G}_{\mathrm{i}}$ & Ranking & $\mathrm{S}_{\mathrm{i}}$ & Ranking & $\mathrm{A}_{\mathrm{i}}$ & Ranking & $\mathrm{Z}_{\mathrm{i}}$ \\
\hline CNA 8555 & 1998 & 0.773 & $1 \mathrm{st}$ & 3,581 & $1 \mathrm{st}$ & 3,616 & $1 \mathrm{st}$ & 1.133 & $1 \mathrm{st}$ & 1.133 \\
\hline Uruçuí & 1989 & 0.813 & 2nd & 3,546 & 17 th & 3,473 & $3 \mathrm{rd}$ & 1.119 & $3 r d$ & 1.119 \\
\hline AB 062008 & 2009 & 0.807 & $3 r d$ & 3,546 & $2 \mathrm{nd}$ & 3,600 & 4 th & 1.112 & 4 th & 1.112 \\
\hline AB 062041 & 2009 & 0.807 & 4 th & 3,514 & 4 th & 3,567 & 5 th & 1.102 & 5 th & 1.101 \\
\hline BRA 02601 & 2005 & 0.867 & 5 th & 3,502 & 6 th & 3,556 & 7 th & 1.097 & 7 th & 1.096 \\
\hline BRS Esmeralda & 2007 & 0.826 & 6 th & 3,499 & $3 r d$ & 3,597 & 8 th & 1.096 & 8 th & 1.094 \\
\hline BRS Colosso & 2001 & 0.875 & 7 th & 3,498 & 8 th & 3,548 & 9 th & 1.094 & 9th & 1.093 \\
\hline BRS Liderança & 2000 & 0.925 & 8 th & 3,494 & 7 th & 3,549 & 10th & 1.091 & 10th & 1.091 \\
\hline BRA 052015 & 2008 & 0.829 & 9th & 3,462 & 5 th & 3,562 & 13 th & 1.083 & 13th & 1.082 \\
\hline CNA 4143 & 1985 & 0.780 & 10th & 3,446 & 62 th & 3,297 & 12 th & 1.086 & 12 th & 1.086 \\
\hline CNA 4146 & 1985 & 0.750 & 11 th & 3,439 & 44th & 3,367 & 11th & 1.087 & 11 th & 1.086 \\
\hline BRA 052034 & 2008 & 0.865 & 12 th & 3,430 & 14 th & 3,499 & 19th & 1.073 & 19th & 1.073 \\
\hline CNA 7680 & 1993 & 0.817 & 13th & 3,419 & 53th & 3,319 & 15 th & 1.076 & 15 th & 1.075 \\
\hline CNAs 8984 & 2001 & 0.875 & 14 th & 3,417 & 18th & 3,466 & 22th & 1.068 & 23 th & 1.068 \\
\hline BRA 032033 & 2006 & 0.871 & 15 th & 3,414 & 12 th & 3,500 & 23th & 1.068 & 22 th & 1.068 \\
\hline BRA 01600 & 2004 & 0.835 & 16th & 3,412 & 16th & 3,482 & 24th & 1.068 & 24th & 1.067 \\
\hline BRA 052053 & 2008 & 0.829 & 17 th & 3,412 & 10th & 3,510 & 26th & 1.067 & 25 th & 1.067 \\
\hline CNA 6682 & 1990 & 0.699 & 18th & 3,408 & 13th & 3,499 & 18 th & 1.074 & 18th & 1.073 \\
\hline A $8-204-1$ & 1989 & 0.783 & 19th & 3,398 & 60th & 3,298 & 21 th & 1.069 & 21 th & 1.068 \\
\hline CNA 7926 & 1994 & 0.702 & 20th & 3,397 & 98th & 3,213 & 16th & 1.075 & 16th & 1.074 \\
\hline AB 062037 & 2009 & 0.807 & 21 th & 3,395 & 24th & 3,444 & 27 th & 1.064 & 27 th & 1.063 \\
\hline CNA 8548 & 1998 & 0.836 & 22 th & 3,394 & 36th & 3,397 & 29th & 1.062 & 28th & 1.062 \\
\hline CNA 4216 & 1986 & 0.662 & 23th & 3,386 & 41th & 3,376 & 14th & 1.077 & 14th & 1.076 \\
\hline BRS Pepita & 2002 & 0.875 & 24th & 3,385 & 22 th & 3,449 & 33th & 1.059 & 35 th & 1.058 \\
\hline BRA 01596 & 2004 & 0.894 & 25 th & 3,385 & 23th & 3,448 & 34 th & 1.059 & 32 th & 1.058 \\
\hline BRS Talento & 1998 & 0.936 & 26th & 3,384 & 34 th & 3,406 & 37 th & 1.058 & 37 th & 1.057 \\
\hline Aimoré & 1993 & 0.859 & 40th & 3,330 & 102th & 3,207 & 52 th & 1.044 & 52 th & 1.043 \\
\hline Carajás & 1990 & 0.931 & 47 th & 3,320 & 65 th & 3,293 & 54 th & 1.040 & 55 th & 1.039 \\
\hline BRS Monarca & 2002 & 0.875 & 58 th & 3,291 & 46th & 3,353 & 65 th & 1.029 & 66th & 1.028 \\
\hline BRS Bonança & 1996 & 0.955 & 59 th & 3,288 & 58 th & 3,306 & 68th & 1.027 & 69th & 1.027 \\
\hline Maravilha & 1990 & 0.938 & 60th & 3,288 & 83th & 3,246 & 70th & 1.027 & 70th & 1.026 \\
\hline Canastra & 1992 & 0.933 & 65 th & 3,278 & 76th & 3,260 & 73th & 1.024 & 73th & 1.024 \\
\hline Rio Paranaíba & 1984 & 0.904 & 66th & 3,277 & 71th & 3,269 & 71th & 1.026 & 71th & 1.026 \\
\hline Xingu & 1986 & 0.859 & 69th & 3,268 & 88th & 3,236 & 74th & 1.023 & 75 th & 1.023 \\
\hline BRS Sertaneja & 2002 & 0.932 & 71th & 3,267 & 48th & 3,332 & 80th & 1.021 & 82 th & 1.019 \\
\hline Cabaçu & 1984 & 0.836 & 75 th & 3,262 & 139th & 3,132 & 78th & 1.021 & 78th & 1.021 \\
\hline Guarani & 1984 & 0.911 & 79th & 3,261 & 99th & 3,213 & 82 th & 1.020 & 81 th & 1.020 \\
\hline Progresso & 1990 & 0.920 & 82 th & 3,255 & 104th & 3,206 & 85 th & 1.017 & 87 th & 1.017 \\
\hline BRSMG Curinga & 2000 & 0.944 & 89th & 3,242 & 61 th & 3,298 & 94th & 1.013 & 95 th & 1.012 \\
\hline Rio Paraguai & 1985 & 0.836 & 91th & 3,238 & 154th & 3,108 & 91th & 1.013 & 91th & 1.013 \\
\hline Araguaia & 1984 & 0.913 & 96th & 3,233 & 105th & 3,204 & 97th & 1.011 & 97 th & 1.011 \\
\hline Acrefino & 1993 & 0.488 & 119th & 3,213 & 119th & 3,176 & 117 th & 1.005 & 115th & 1.005 \\
\hline
\end{tabular}


Table 2 continued

\begin{tabular}{|c|c|c|c|c|c|c|c|c|c|c|}
\hline Elite-line & VCU & $\hat{\mathbf{r}}_{\hat{\mathrm{g} g}}$ & Ranking & $\mathrm{G}_{\mathrm{i}}$ & Ranking & $\mathrm{S}_{\mathrm{i}}$ & Ranking & $\mathrm{A}_{\mathrm{i}}$ & Ranking & $\mathrm{Z}_{\mathrm{i}}$ \\
\hline Tangará & 1986 & 0.832 & 125 th & 3,210 & 217 th & 2,982 & 126th & 1.003 & 125 th & 1.003 \\
\hline BRS Primavera & 1995 & 0.963 & 145 th & 3,185 & 92th & 3,225 & 140th & 0.996 & 144th & 0.995 \\
\hline Carisma & 1996 & 0.924 & 157 th & 3,162 & 127 th & 3,152 & 157 th & 0.988 & 157 th & 0.987 \\
\hline Rio Verde & 1988 & 0.818 & 160th & 3,161 & 208th & 3,002 & 161th & 0.985 & 160th & 0.985 \\
\hline Caiapó & 1989 & 0.937 & 163th & 3,158 & 150th & 3,110 & 160th & 0.986 & 161th & 0.985 \\
\hline Centro América & 1985 & 0.826 & 168th & 3,155 & 218th & 2,979 & 163th & 0.985 & 163th & 0.984 \\
\hline Mearim & 1984 & 0.402 & 170th & 3,154 & 163th & 3,084 & 183th & 0.977 & 183th & 0.976 \\
\hline BRS Caripuna & 1997 & 0.895 & 172 th & 3,147 & 108th & 3,202 & 166th & 0.983 & 169th & 0.982 \\
\hline BRS Vencedora & 2000 & 0.897 & 175 th & 3,147 & 110th & 3,199 & 165 th & 0.984 & 165 th & 0.983 \\
\hline Confiança & 1993 & 0.894 & 202th & 3,110 & 206th & 3,003 & 195th & 0.969 & 195th & 0.969 \\
\hline Douradão & 1988 & 0.652 & 250th & 3,014 & 180th & 3,054 & 240th & 0.936 & 239th & 0.935 \\
\hline BRS Soberana & 1999 & 0.904 & 261th & 2,922 & 216 th & 2,982 & 253th & 0.913 & 253th & 0.912 \\
\hline$\vdots$ & $\vdots$ & $\vdots$ & $\vdots$ & $\vdots$ & $\vdots$ & $\vdots$ & $\vdots$ & $\vdots$ & $\vdots$ & $\vdots$ \\
\hline CNA 7296 & 1990 & 0.486 & 265 th & 2,781 & 264th & 2,541 & 265 th & 0.792 & 265 th & 0.784 \\
\hline
\end{tabular}

relationship. These cultivars are double haploid, developed by the anther culture method after a twoway crossing between Kaybonnet and Aimoré. Kaybonnet is a lowland rice cultivar from the USA with excellent grain quality. Aimoré is an upland rice cultivar from Brazil that is very rustic and has a short cycle. Despite the vast potential that these cultivars exhibited (Table 2), BRS Liderança was suspended even before seed marketing, and BRS Colosso was dropped soon after the first year of commercial growing because the GY was rigorously affected due to the breakdown of the rice panicle blast resistance (Magnaporthe oryzae) such that previously tolerant elite-lines became highly susceptible (Prabhu et al. 2009).

BRS Pepita is a current cultivar in Embrapa's portfolio, which simultaneously presented an excellent GY (24th ranking for $\mathrm{G}_{\mathrm{i}}$ ) and superiority in adaptability and stability compared to other current cultivars, including BRS Monarca, BRS Bonança and BRS Sertaneja. BRS Pepita, in addition to having a very stable GY across different locations and years (22nd position for $\mathrm{S}_{\mathrm{i}}$ ), also demonstrated a capacity to respond positively to agricultural inputs, such as fertilisers and irrigation (33rd position for $A_{i}$ ). The superiority of BRS Pepita was $5.76 \%\left(\mathrm{Z}_{\mathrm{i}}\right)$ above the general mean for GY considering all genotypes, locations and years (Table 2). BRS Pepita was released in 2007 and was developed from a two-way crossing between the elite-lines CNA 7680 and CNA 7726. It is a rustic cultivar with an early cycle and is resistant to grain discoloration (caused by a complex of fungi). It is likely that the parent CNA 7680 majorly contributed to the exceptional performance of BRS Pepita, as this parent is highlighted by high GY associated with a great adaptability (15th position for $\mathrm{A}_{\mathrm{i}}$, Table 2). In another study, this parent also presented high efficiency in using available phosphorus in low-level soil conditions (Fageria and Baligar 1997). For upland rice sustainability, high efficiency in using both nutrients and water from the soil is fundamental because more than half of the producing areas occur in "cerrado", where soils are characterised as having low water-storage capacity, low phosphorus and high aluminium, limiting rice growth (Crusciol et al. 2005). The low water-storage capacity of soils, together with high evapotranspiration demand during dry spells periods (known as "veranicos" in Portuguese), cause serious decreases and oscillations in GY.

It was very interesting to note that three elite-lines from the current Embrapa pipeline were among the best for GY $\left(\mathrm{G}_{\mathrm{i}}\right)$ and demonstrated excellent adaptability and stability (Table 2). They were AB 062008, AB 062041 and AB 062037, which have germplasm from Embrapa (BRS Liderança as sources to improve the potential for GY; BRS Soberana as sources mainly for grain quality), the International Center for Tropical Agriculture-CIAT (BRS Bonança and BRS Talento 
as relevant sources to improve the potential for GY and modern plant architecture) and other elite-lines mainly as sources of resistance to rice blast (Fig. 1). In Fig. 1, BRS Atalanta is a lowland rice cultivar of the Embrapa (subspecies indica), and Cuiabana was the first upland rice cultivar in Brazil with resistance to rice blast, while CNAx 1235-8-3 has an early cycle and quality grain, and CNA 6673 has good drought tolerance and plant architecture.

Thus, these three elite-lines showed high values of $S_{i}, A_{i}$ and $Z_{i}$, reflecting a high potential to be released as cultivars in Brazil, associating simultaneously excellent GY with great adaptability and stability across locations and years. These attributes are fundamental for upland rice, considering that production occurs in a wide range of environments, ranging from most to less risky for production according to rainfall and from high to low technological level among farmers (Pinheiro et al. 2006).

A generalised linear regression analysis was performed with all cultivars and the three elite-lines from the Embrapa pipeline during the period from 1984 to 2010 to evaluate the genetic progress on stability $\left(\mathrm{S}_{\mathrm{i}}\right.$, Fig. 2) and adaptability $\left(\mathrm{A}_{\mathrm{i}} \overline{\mathrm{M}}\right.$, Fig. 3) associated with GY in Embrapa's upland rice breeding program using the HMRPGV method.

In this period, there was a significant increase $(\mathrm{p} \leq 0.01)$ of the stability (Fig. 2$)$ and adaptability (Fig. 3) of the cultivars released during these years. During the first phase (1984-1995), there was not a clear trend of increase in stability $\left(\mathrm{S}_{\mathrm{i}}\right)$ or adaptability $\left(A_{i} \bar{M}\right)$, but there was in the second phase (1996-2010).
These results corroborate the study of Breseghello et al. (2011), which evaluated the genetic gain resulting from Embrapa's upland rice breeding program in the period from 1984 to 2009 using a mixed model. These authors observed the following for GY: from 1984 to 1992, the gain for GY was nonsignificant; from 1992 to 2002, the yearly gain was $15.7 \mathrm{~kg} \mathrm{ha}^{-1}$ year $^{-1}$; and from 2002 to 2009 , the yearly gain was $45.0 \mathrm{~kg} \mathrm{ha}^{-1}$ year $^{-1}$.

Initially, grain quality was not a strong priority in the upland rice breeding program because the long and bold grains of traditional upland cultivars were considered the standard for quality. However, during the 1980s, due to a supply of rice from USA cultivars (e.g., Labelle, Bluebelle and Lebonnet) produced in Southern Brazil, the Brazilian consumers began to prefer long and slender grains, without a white core, with a translucent, glossy and uniform milled-grain appearance, and with a dry and fluffy texture when cooked. Therefore, the effort to improve the grain quality of upland rice in Brazil began as a reference to the grain quality from USA cultivars, which were used in crossings (Pinheiro et al. 2005). Thus, in this period (1984-1995), the stability $\left(S_{i}\right)$ and adaptability $\left(A_{i} \bar{M}\right)$ of GY were affected because of changing the main target trait, which became grain quality. Additionally, the introgression of indica germplasm from lowland rice (USA germplasm) to improve grain quality may have decreased the adaptation of rice to the upland environment, although there have been releases of improved plant type cultivars for savannah conditions since the early 1990s. The biggest impact was attained

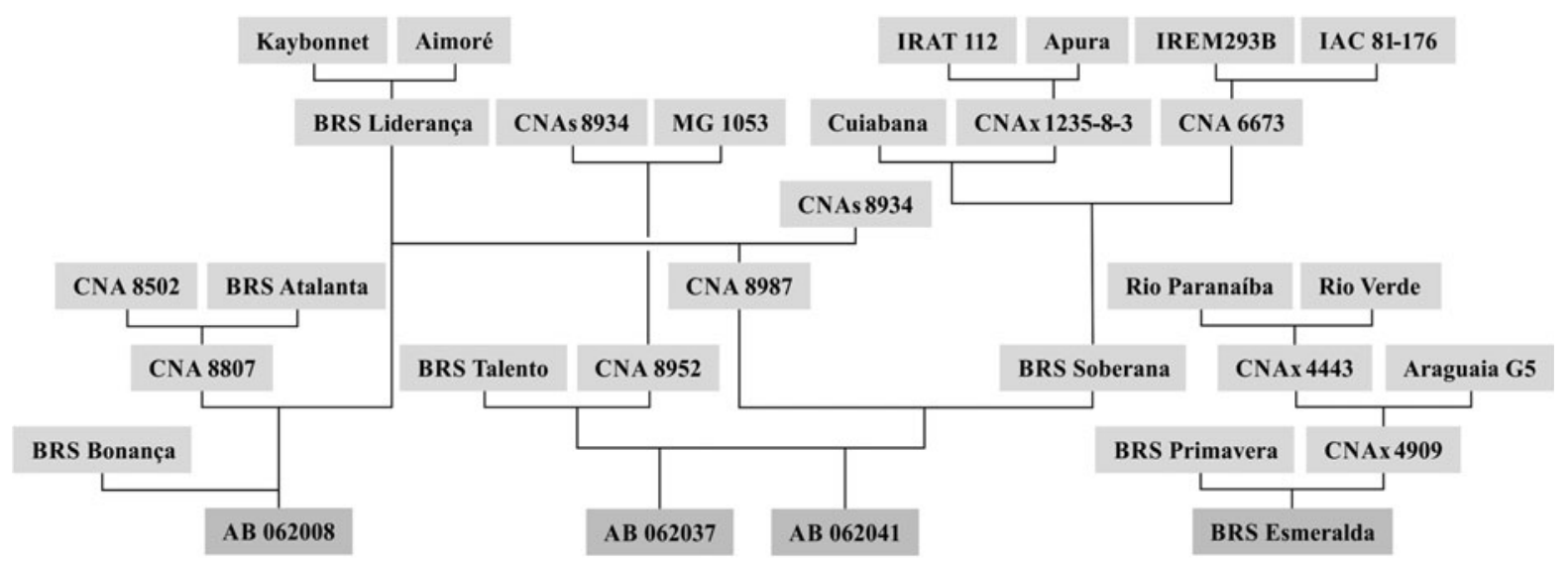

Fig. 1 Genealogies of the new cultivar, BRS Esmeralda, and of the three latest elite-lines, AB 062008, AB 062037 and AB 062041, from Embrapa's upland rice breeding program 


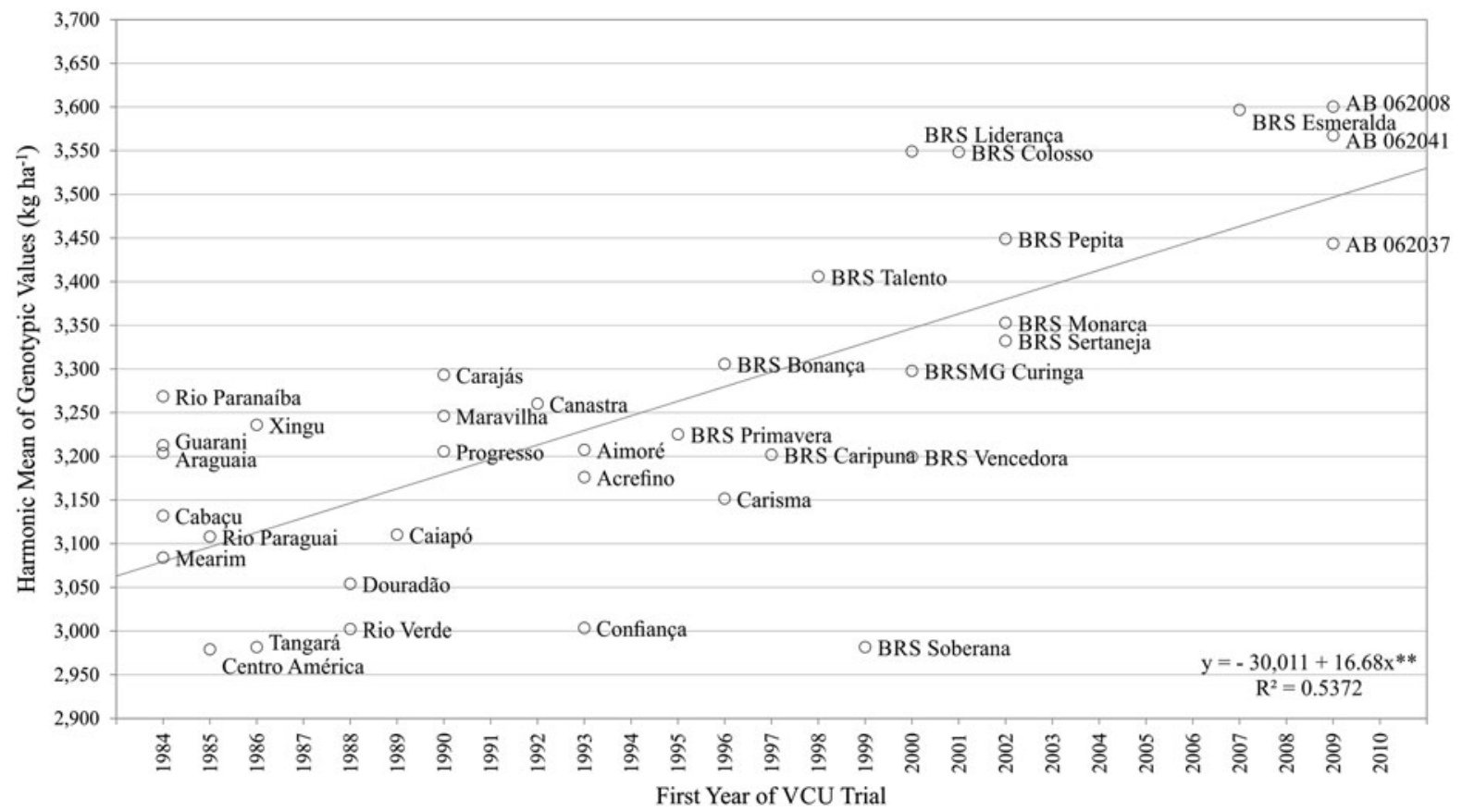

Fig. 2 Evolution of the stability by Harmonic Mean of Genotypic Values $\left(\mathrm{S}_{\mathrm{i}}, \mathrm{kg} \mathrm{ha}^{-1}\right)$ over time in the upland rice breeding program within the study period (1984-2010), based on the joint analysis of a dataset from seven Brazilian states.

with cultivar BRS Primavera, released in 1997 from a crossing between IRAT 10 (CIRAD's germplasm) and LS 85-158 to improve the grain traits (Brondani et al. 2006). It was the first upland cultivar that combined high grain quality and desirable upland rice ideotype (Pinheiro 1999).

The second phase (1996-2010) was marked by a strong influence of introduced genotypes from the USA and CIAT (Breseghello et al. 2011) and by the important collaborative projects with the French Center for International Cooperation in Development-oriented Agricultural Research/Institute for Research in Tropical Agriculture (CIRAD/IRAT) that had been established after the first phase. The CIAT's germplasm strongly contributed to the selection of shorter plants and lodging resistance that were needed for the upland rice to thrive in the environments with high agricultural inputs and with a fully mechanised cropping system (Morais et al. 2006). Furthermore, there were other traits from CIAT's germplasm that were relevant for improving the potential for GY, such as abundant and upright tillering, short and erect flag leaves and lower panicles in the canopy (Breseghello et al. 2011).
Round white dots refer to the $\mathrm{S}_{\mathrm{i}}$ values of the cultivars and the three latest elite-lines debuted in the VCU trial that year. A generalised linear regression equation was given for $\mathrm{S}_{\mathrm{i}}$ values over years, with $\alpha=0.01\left({ }^{* *}\right)$ level of significance by the $t$ test

Seven cultivars were released resulting from genotypes introduced from CIAT: Progresso, Maravilha, Canastra, BRS Bonança, Carisma, BRS Talento and BRSMG Curinga. BRS Sertaneja, BRS Monarca and BRS Pepita are important cultivars of Embrapa's portfolio, and all resulted from crossings made between CIAT parents and other materials to improve the grain traits.

In the current stage of Embrapa's breeding program, efforts have been concentrated on selection to increase GY, stability and adaptability, keeping other traits within a suitable range (e.g., grain quality, plant height and days-to-flowering) and with few gains for disease resistance. Breseghello et al. (2011) observed the highest estimate of genetic gain for GY in this period (2002-2009), equal to $1.44 \%$ per year, corroborating the observed values for $\mathrm{S}_{\mathrm{i}}$ (Fig. 2) and $\mathrm{A}_{\mathrm{i}} \overline{\mathrm{M}}$ (Fig. 3), which simultaneously considered more attributes, including stability and adaptability. It is noteworthy that because of the high $\mathrm{G} \times \mathrm{E}$ confirmed in this study (Table 1), it would be impossible to obtain a genotype with wide adaptability and stability that would grow in a region as extensive and heterogeneous as Brazil. 


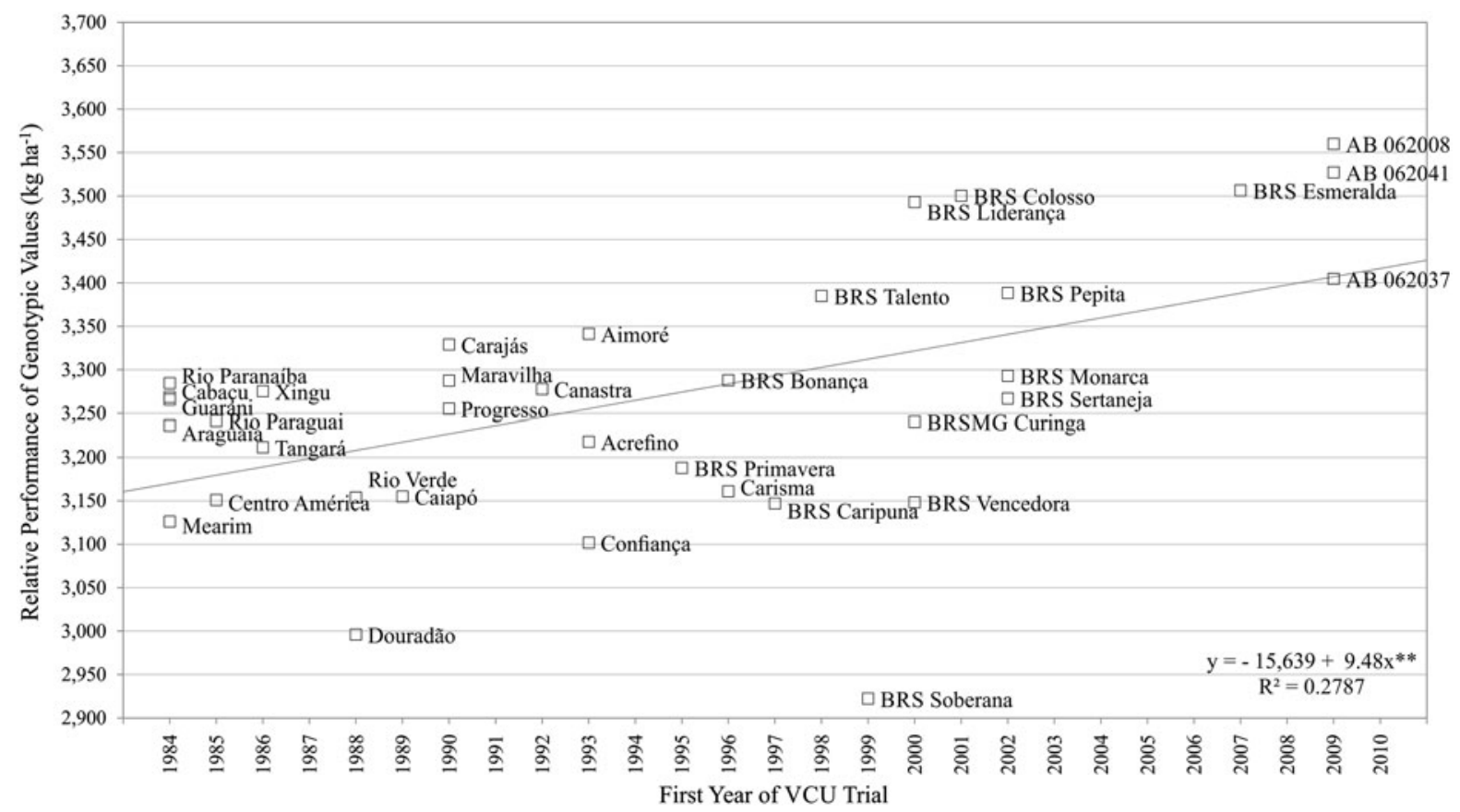

Fig. 3 Evolution of adaptability by Relative Performance of Genotypic Values $\left(\mathrm{A}_{\mathrm{i}} \overline{\mathrm{M}}, \mathrm{kg} \mathrm{ha}^{-1}\right)$ over time in the upland rice breeding program within the study period (1984-2010) based on the joint analysis of a dataset from seven Brazilian states. Square

It is important to comment that selection for disease resistance, mainly rice blast resistance, has always been a very important factor during the entire study period, surpassing the importance of even higher gains for GY, adaptability and stability. In Brazil, rice blast has been the most aggressive pathogen of upland rice (Filippi et al. 2007); it directly affects the GY and stability of susceptible genotypes. In Embrapa's program, only rice blast susceptibility is a motive for discarding elite-lines, even if they are high-yielding.

During the period involved in this study (1984-2010), the increasing gains in stability and adaptability associated with GY within the cultivars culminated with the selection of BRS Esmeralda, which had the best values of $S_{i}, A_{i}$ and $Z_{i}$ (Table 2; Figs. 1,2). This is the most recent cultivar of upland rice in the Embrapa program, which has a scheduled date for release in 2013.

BRS Esmeralda originated from a two-way crossing between CNAx 4909 and BRS Primavera (Fig. 1). The elite-line CNAx 4909 has a germplasm from traditional cultivars for providing vigorous plants to increase white dots refer to the $\mathrm{A}_{\mathrm{i}} \overline{\mathrm{M}}$ values of the cultivars and the three latest elite-lines debuted in the VCU trial that year. A generalised linear regression equation was given for $A_{i} \bar{M}$ values over years, with $\alpha=0.01(* *)$ level of significance by the $t$ test

capacity for competition with weeds (Araguai G5, which is a mutant of the cultivar Araguaia with long and slender grain, and Rio Paranaíba) and for increasing drought tolerance (Rio Verde or IRAT 216). Additionally, this cultivar has a stay-green characteristic, which has usually been considered to be associated with the retention of high photosynthetic capacity and yield increment (Thomas and Howarth 2000).

Finally, the HMRPGV method was shown to be an important and practical tool for simultaneous identification of elite-lines that are stable, adapted and capable of high yield potential across locations and years. The method allowed the identification two elitelines (AB 062008 and AB 062041) from the Embrapa pipeline with $\mathrm{Z}_{\mathrm{i}} \overline{\mathrm{M}}$ values greater than those of current cultivars (BRS Pepita, BRS Monarca and BRS Sertaneja) and greater than that of the best cultivar, BRS Esmeralda. Thus, the release of some of these elitelines as cultivars would consolidate further gains for upland rice in Brazil, with a high GY associated with great adaptability and stability to a large range of soils, climates and styles of crop management on the 
"cerrado", which cover an area of about 200 million hectares (Pinheiro et al. 2006).

Acknowledgments We thank the entire rice breeding team of Embrapa, especially the research assistants and field workers who performed the VCU trials and collected the data used in our study.

\section{References}

Annicchiarico P (1992) Cultivar adaptation and recommendation from alfalfa trials in northern Italy. Indian $\mathrm{J}$ Genet Breed 46:269-278

Atroch AL, Soares AA, Ramalho MAP (2000) Adaptability and stability of lineages of upland rice evaluated in Minas Gerais. Ciência e Agrotecnologia 24:541-548

Baker RJ (1990) Crossover genotype-environmental interaction in spring wheat. In: Kang MS (ed) Genotype-by-environment interaction and plant breeding. Louisiana State University Agricultural Center, Baton Rouge, pp 42-51

Bastos IT, Barbosa MHP, Resende MDV, Peternelli LA, Silveira LCI, Donda LR, Fortunato AA, Costa PMA, Figueiredo ICR (2007) Evaluation of genotype versus environment interaction in sugarcane using mixed models. Pesquisa Agropecuária Trop 37:195-203

Borges V, Soares AA, Reis MS, Resende MDV, Cornélio VMO, Leite NA, Vieira AR (2010) Genotypic performance of lines of the upland rice using mixed model. Bragantia 69:833-841

Breseghello F, Morais OP, Pinheiro PV, Silva ACS, Castro EM, Guimarães EP, Castro AP, Pereira JA, Lopes AM, Utumid MM, Oliveira JP (2011) Results of 25 years of upland rice breeding in Brazil. Crop Sci 51:914-923

Brondani C, Caldeira KS, Borba TCO, Rangel PN, Morais OP, Castro EM, Rangel PHN, Mendonça JA, Brondani RV (2006) Genetic variability analysis of elite upland rice genotypes with SSR markers. Crop Breed Appl Biotechnol 6:9-17

Carbonell SAM, Chiorato AF, Resende MDV, Dias LAS, Beraldo ALA, Perina EF (2007) Stability of common bean cultivars and lines in different environments in the state of Sao Paulo. Bragantia 66:193-201

Cockerham CC (1963) Estimation of genetic variances. In: Hanson WD, Robinson HF (eds) Statistical genetics and plant breeding. National Academy of Science, Washington, DC, pp 53-94

Crusciol CAC, Mauad M, Alvarez RCF, Lima EV, Tiritan CS (2005) Phosphorus doses and root growth of upland rice. Bragantia 64:643-649

Cruz CD, Castoldi FL (1991) Simple and complex decomposition in parts of the genotypes $\mathrm{x}$ environments interaction. Revista Ceres 38:422-430

Cruz CD, Regazzi AJ, Carneiro PCS (2004) Modelos biométricos aplicados ao melhoramento genético. UFV, Viçosa

Fageria NK, Baligar VC (1997) Upland rice genotypes evaluation for phosphorus use efficiency. J Plant Nutr 20:499-509

Filippi MCC, Silva GB, Prabhu AS (2007) Induction of leaf blast resistance in rice by an avirulent isolate of Magnaporthe oryzae. Fitopatologia Brasileira 32:387-392
Henderson CR (1984) Applications of linear models in animal breeding. University of Guelph, Ontario

Kang MS (1998) Using genotype-by-environment interaction for crop cultivar development. Adv Agron 62:199-252

Lin CS, Binns MR (1988) A superiority measure of cultivar performance for cultivar $\mathrm{x}$ location data. Can J Plant Sci 68:193-198

Maia MCC, Resende MDV, Paiva JR, Cavalcanti JJV, Barros LM (2009) Simultaneous selection for genotypic production, adaptability, and stability in cashew clones by mixed models. Pesquisa Agropecuária Trop 39:43-50

Mariotti JA, Oarzabal ES, Osa JM, Bulacio ANR, Almada GH (1976) Analisis de stabilidad y adaptabilidad de genótipos de cãna de azucar. I. Interacciones dentro de una localidad experimental. Revista Agronómica Norte Argentina 13: 405-412

Morais OP, Rangel PHN, Fagundes PRR, Castro EM, Neves PCF, Cutrim VA, Prabhu AS, Brondani C, MagalhãesJunior AM (2006) Melhoramento Genético. In: Santos AB, Stone LF, Vieira NRA (eds) A cultura do arroz no Brasil. Embrapa Arroz e Feijão, Santo Antônio de Goiás, pp 289-358

Oliveira RA, Resende MDV, Daros E, Bespalhok-Filho JC, Zambon JLC, Ido OT, Weber H, Koehler HS (2005) Genotypic evaluation and selection of sugarcane clones in three environments in the state of Paraná. Crop Breed Appl Biotechnol 5:426-434

Pinheiro BS (1999) Características morfológicas da planta relacionadas à produtividade. In: Vieira NRA, Santos $\mathrm{AB}$ (eds) A cultura do arroz no Brasil. Embrapa Arroz e Feijão, Santo Antônio de Goiás, pp 116-147

Pinheiro BS, Castro EM, Moraes OP, Breseghello F (2005) Developing aerobic rice in Brazil. In: Toriyama K, Heong KL, Hardy B (eds) Rice is life: scientific perspectives for the 21 st century, Proceedings of the world rice research conference, Tsukuba, pp 154-156

Pinheiro BS, Castro EM, Guimarães CM (2006) Sustainability and profitability of aerobic rice production in Brazil. Field Crops Res 97:34-42

Prabhu AS, Filippi MCC, Silva GB, Silva VL, Morais OP (2009) An unprecedented outbreak of rice blast on a newly released cultivar BRS Colosso in Brazil. In: Wang GL, Valent B (eds) Advances in genetics, genomics and control of rice blast disease. Springer Science, Netherlands, pp 257-266

Resende MDV (2007a) Matemática e estatística na análise de experimentos e no melhoramento genético. Embrapa Florestas, Colombo

Resende MDV (2007b) SELEGEN-REML/BLUP: Sistema estatístico e seleção genética computadorizada via modelos lineares mistos. Embrapa Florestas, Colombo

Resende MDV, Duarte JB (2007) Precision and quality control in variety trials. Pesquisa Agropecuária Trop 37:182-194

Singh AK, Payasi SK (1999) Stability assessment in early duration genotypes of rice. Crop Res 18:433-436

Singh M, Ceccarelli S, Grando S (1999) Genotype x environment interaction of crossover type: detecting its presence and estimating the crossover point. Theor Appl Genet 99:988-995

Steel RGD, Torrie JH (1997) Principles and procedures of statistics: a biometrical approach. McGraw-Hill, New York 
Thomas H, Howarth CJ (2000) Five ways to stay green. J Exp Bot 51:329-337

Vencovsky R, Barriga P (1992) Genética biométrica no fitomelhoramento. Sociedade Brasileira de Genética, Ribeirão Preto

Verardi CK, Resende MDV, Costa RB, Gonçalves PS (2009) Adaptability and stability of rubber production and selection in rubber tree progenies. Pesquisa Agropecuária Brasileira 44:1277-1282

Zeni-Neto H, Oliveira RA, Daros E, Bespalhok-Filho JC, Zambon JLC, Ido OT, Weber H (2008) Selection for yield, adaptability and stability of sugarcane clones in three environments of Parana state via mixed models. Scientia Agraria 9:425-430 